\title{
La penetración económica portuguesa en la Sevilla del siglo XVI*
}

\author{
Manuel F. Fernández Chaves-Rafael M. Pérez García \\ Universidad de Sevilla
}

\section{The Portuguese economic penetration in Seville in the 16th century}

\begin{abstract}
RESUMEN
El presente artículo estudia el proceso de penetración económica del capital portugués en la Sevilla del siglo XVI. Desde unos orígenes modestos, su papel privilegiado en la trata negrera atlántica permitió a una serie de redes mercantiles portuguesas ir ocupando espacios cada vez mayores no sólo de la economía urbana hispalense sino también en el gran y complejo negocio que era la trata de esclavos hacia las Indias de Castilla.
\end{abstract}

\section{PALABRAS CLAVE:}

Sevilla, siglo XVI, Portugueses, Redes, Trata de esclavos.

\section{ABSTRACT}

In this paper, the authors analyse the economical settlement of the portuguese capitals in the Sixteenth century Seville. From humble origins, their privileged role in the Atlantic slave trade let an array of different mercantile portuguese networks to occupy each time wider spaces not only in the urban sevillian economy but also in the big and complex bussiness of the slave trade to the Castile Indies.

\section{KEY WORDS:}

Seville, Sixteenth Century, Portuguese, Networks, Slave Trade.

* El presente trabajo se ha realizado en el marco del Proyecto I+D «Nobles judeoconversos. El origen judío de las élites andaluzas (ss. XV-XVII)» (HAR2012-35752), concedido por el Ministerio de Economía y Competitividad. 


\section{LA UNIÓN DE LAS CORONAS Y LA PENETRACIÓN PORTUGUESA EN SEVILLA: UN PROBLEMA HISTORIOGRÁFICO}

Hoy sabemos que en 1580 los portugueses ya gozaban de fama de riqueza en Sevilla y que los más pudientes de ellos tendían a agruparse en la collación de San Salvador y la calle Sierpes. Las investigaciones realizadas en junio de ese año con motivo del descubrimiento de una conspiración que tramaban ciertos moriscos de la ciudad para rebelarse aprovechando la marcha de los hombres a la guerra en Portugal, nos ofrecen un testimonio harto significativo ${ }^{1}$. Junto a la iglesia de San Bartolomé se construía una casa; en la obra trabajaban mano con mano un maestro de obra sevillano, un carpintero portugués y un albañil morisco. En el mes de marzo de aquel año, en el contexto de una ciudad conmocionada por los rumores de una posible intervención militar en el vecino reino de Portugal, se produjo la siguiente conversación:

«y el dicho García morisco dixo: «ahora os yréis todos vosotros a la guerra e nos quedaremos nosotros los moriscos con vuestras mujeres», lo qual decía a los christianos viejos que estavan allí, los quales le respondieron que era un perro e que no hablase aquellas palabras, y luego el dicho García tornó a decir: «yo tengo de entrar por la calle de la Sierpe y tengo de captivar los primeros portugueses más ricos que allí estuvieren», y el dicho portugués carpintero que allí estava respondió: "ibendito sea Dios que venga un perro vellaco morisco a dezir que ha de captivar los portugueses!». Y con esto cesó la plática»².

Si bien es cierto que este testimonio se hace eco de una realidad innegable en 1580, sin embargo, el proceso histórico por el que los portugueses penetraron en Sevilla a lo largo del siglo XVI no ha sido todavía satisfactoriamente explicado. La Unión de las Coronas y la presión de la Inquisición portuguesa no fueron las razones decisivas para explicar la presencia de una activa y rica colonia mercantil portuguesa en Sevilla, como a veces se ha sugerido, por más que la primera facilitase indudablemente a los portugueses el comercio y la trata negrera con las Indias de Castilla $^{3}$. El proceso venía de antes.

Fernand Braudel explicó el éxito portugués en Sevilla a partir de la década de 1570 en relación con las mutaciones que el sistema económico y marítimo internacional experimentó desde 1566-1567, con la rebelión de los Países Bajos, la llegada del duque de Alba a los mismos, el recrudecimiento de la piratería inglesa, las dificultades españolas para mantener abierta la ruta marítima hacia el norte y la consecuente asfixia de una Amberes privada de los metales preciosos procedentes de América ${ }^{4}$. Las concesiones de Felipe II a los mercaderes genoveses para realizar «sacas de plata» les habrían permitido desinteresarse de «la expor-

1 FERNÁNDEZ CHAVES y PÉREZ GARCÍA, 2009, 271/293.

2 Archivo General de Simancas (AGS): Consejo Real, leg. 257/4.

${ }^{3}$ MORALES PADRÓN, 1989, 83/84.

${ }^{4}$ BRAUDEL, 2005 1, 637/641. 
tación de mercancías que hasta aquel momento habían facilitado sus pagos al norte» ${ }^{5}$. Morales Padrón también se refiere a que las licencias dadas en 1566 a los genoveses para transferir la plata les permitieron poder prescindir de los riesgos del comercio americano: «la ciudad por eso se verá privada de una actividad mercantil, que es sustituida por la financiera, pero el tráfico no cesa, ya que los flamencos hacen el relevo» ${ }^{6}$. Estos ocuparían el hueco dejado por los genoveses en lo referente al comercio de mercancías, y explicaría que a finales del siglo XVI hubiese en Sevilla 200 casas flamencas ${ }^{7}$. También Felipe Ruiz Martín se ha referido a la trascendencia de que a partir de 1566 empezasen a figurar las licencias de saca en los asientos con los genoveses ${ }^{8}$. Braudel, que sigue la obra de Jacob van Klaveren, coincide con esta explicación: el hueco dejado por la retirada del capitalismo genovés del comercio de exportación de Sevilla habría sido ocupado por los mercaderes de los Países Bajos. Los mercaderes sevillanos, por su parte, "se convierten ahora en unos meros agentes con comisión», que "nunca arriesgan lo suyo» y cuyos capitales «van a servir para comprar tierras y pueblos, juros, o para constituir mayorazgos»; y concluye drásticamente: «De este papel pasivo a la completa inactividad sólo había un paso y ellos contemplan tranquilamente tal perspectiva». Frente a esta pasividad, y en el contexto de guerra que se abre desde 1572, Amsterdam, que ha atraído a los mercaderes de Amberes, se apoyará en Sevilla para lanzar «su red sobre la inmensa América española». En la década de 1590 el comercio que se realiza a través de Sevilla estaría ya en manos, fundamentalmente, de extranjeros. El recurso a testaferros, hombres de paja, la corrupción y el contrabando habrían sido las claves del proceso ${ }^{9}$. Y en todo él, los portugueses habrían jugado un papel clave para Braudel: «los ricos marranos portugueses entran en juego para preparar y facilitar - muchas veces sin pretenderlo- el camino a los holandeses: Ios Ximenes de Lisboa y de Amberes, por ejemplo, y sus asociados, los Andrade y los Veiga, ...», vinculados al comercio de la pimienta hacia el norte y a la introducción del trigo nórdico en el Mediterráneo. Es decir, las redes mercantiles creadas por los marranos portugueses habrían sido los caminos utilizados por los holandeses para apoderarse a renglón seguido de Sevilla y penetrar en el Mediterráneo ${ }^{10}$. Y en otro lugar escribe: «la conexión que a finales del siglo XVI mantienen entre sí los judíos portugueses poseedores de grandes capitales que controlan el comercio del azúcar y de las especias ha

5 Ibídem, 838.

${ }^{6}$ MORALES PADRÓN, 1989, 81.

7 Ibídem, 82-83.

8 RUIZ MARTíN, 1990, 15. En la pág. 24 escribe también: «De 1566 en adelante el capitalismo cosmopolita va deslizándose progresivamente por una pendiente: desdeña las mercaderías y se vuelca sobre las finanzas».

9 BRAUDEL, 2005, 1, 835-841, siguiendo fundamentalmente a Jacob van Klaveren: Europäische Wirtschaftgeschichte Spaniens im 16. und 17. Jahrhundert, Stuttgart, Gustav Fischer Verlag, 1960, especialmente págs. 111ss. Significativamente Braudel llama a este capítulo: «De cómo los holandeses se apoderaron de Sevilla, a partir de 1570, sin hacer un solo disparo».

10 BRAUDEL, 2005 1, 841/843, la cita en 841. 
sido factor decisivo en el crecimiento de la prosperidad de Amsterdam. Y también toda América queda cubierta por su red de relaciones» ${ }^{11}$.

Por su parte, Eufemio Lorenzo Sanz, aunque mostró que los mercaderes portugueses en Sevilla fueron uno de los grupos más numerosos en tiempos de Felipe II (sólo superados por castellanos-sevillanos e italianos) y acertó a señalar la clave de su riqueza (la trata negrera), tampoco parece comprender el desarrollo del proceso del asentamiento de los lusos en la ciudad. Para este autor, que identifica más de una treintena de comerciantes lusos negociando en o con Sevilla en ese reinado, aunque en la década de 1570 ya habrían sido numerosos, «va a ser a partir de 1580, cuando una cifra creciente se va estableciendo en Sevilla, al mismo tiempo que las grandes firmas lisboetas logran dominar el negocio negrero. Aunque no perdieron la condición de extranjeros, sin embargo, de hecho no encontraron grandes dificultades para destacarse en el comercio indiano» ${ }^{12}$.

Sin embargo, la penetración portuguesa en Sevilla y su indiscutible éxito en la misma respondían a un lento progreso que se había venido gestando en torno a una serie de actividades que ellos controlaban, como el comercio de esclavos o el de pastel. Ellos lucharon por conseguir un control de todos los elementos de estos negocios y así fueron desplazando a lo largo del siglo, y paulatinamente, a los grupos financieros y mercantiles no lusos (principalmente genoveses, florentinos, sevillanos y andaluces) de la participación o liderazgo en las mismas, hasta hacerse con el control de los distintos aspectos del negocio: la producción, la comercialización, la financiación y la especulación. El proceso fue muy largo, difícil y complejo, pero desde luego no es explicable sólo a partir de las principales coyunturas específicas del reinado de Felipe II: 1566 y el cierre del norte; la bancarrota de 1575 y los problemas del sistema financiero sevillano; y 1580 con la Unión de las Coronas.

\section{TRATA NEGRERA Y PENETRACIÓN DEL CAPITAL PORTUGUÉS EN SEVILLA}

Los descubrimientos y la expansión portuguesa por el Atlántico y la costa africana a lo largo del siglo XV supusieron el inicio de una nueva etapa en la historia de la esclavitud. Como ya pusiera de manifiesto Charles Verlinden, la nueva trata negrera portuguesa venía a continuar con las tratas mediterráneas que habían florecido en la Baja Edad Media y respondía tanto a las necesidades de financiación de la propia expansión portuguesa, y a los objetivos económicos de esta ${ }^{13}$, como al fenómeno de traslación de los ejes económicos mediterráneos

11 Ibidem, 2005, 2, 219.

12 LORENZO SANZ, 1979 1, 93/102, la cita en 94.

${ }^{13}$ CORTÉS LÓPEZ, 1994, 249/269. 
hacia el Atlántico que los genoveses protagonizan entre los siglos XIV y XVI ${ }^{14}$. La fecha de 1441 no sólo es la del primer cargamento de esclavos negroafricanos llevados por los portugueses a Portugal, simbolizando el comienzo histórico de la trata atlántica, sino que además marca el inicio de un siglo en que el destino prioritario de esa trata negrera cada vez más voluminosa y gestionada por los portugueses fue la Península Ibérica. Los trabajos clásicos de Vicenta Cortés para Valencia y Franco Silva para Sevilla, o los recientes de Raul González Arévalo e Iván Armenteros para Barcelona, han puesto de manifiesto que no sólo Portugal sino todas las regiones costeras andaluzas y levantino-mediterráneas fueron afectadas de forma masiva por aquella primera trata negrera dirigida por los portugueses en las décadas de tránsito del siglo XV al XVI. Antonio Almeida ha recordado que hasta mediados del siglo XVI el destino principal de los esclavos rescatados por los portugueses en las zonas africanas de aprovisionamiento fue la Península Ibérica antes que América ${ }^{15}$. Los valores de población esclava que se alcanzan en Portugal y en Andalucía durante el siglo XVI corroboran desde el lado de la recepción esa valoración ${ }^{16}$.

La ciudad de Sevilla pronto se situó en el corazón de aquel gigantesco y complejo proceso económico. Por un lado, su situación geográfica entre el Mediterráneo y el Atlántico la convirtió ya en el siglo XV en el gran puerto que conectaba aquellos dos espacios económicos, lo que se tradujo en la constitución en la ciudad de importantes colonias de mercaderes y financieros extranjeros que funcionaban como pieza de engarce y actor dinámico en aquella geografía de los negocios sur-norte. Entre esas colonias destacaban, naturalmente, los italianos, especialmente los genoveses y los florentinos, que dominaban de manera absoluta los aspectos financieros de aquella importante circulación de bienes. Otros de origen nórdico (flamencos, ingleses, bretones, ...) estaban básicamente relacionados con actividades de importación-exportación desde sus regiones de origen a partir del centro de distribución que era Sevilla ${ }^{17}$. Aunque las relaciones económicas, humanas, políticas y culturales eran muy estrechas entre el Reino de Sevilla y Portugal a fines de la Edad Media ${ }^{18}$, lo cierto es que el lugar ocupado por los portugueses en las funciones de intermediación del engranaje económico sevillano entre el Mediterráneo y el norte de Europa era realmente marginal. Y ello a pesar, insistimos, de la constatación de una importante presencia portuguesa en Andalucía occidental también en relación con el abastecimiento desde los puertos andaluces de las plazas portuguesas en el norte de África ${ }^{19}$.

\footnotetext{
14 PIKE, 1966.

15 ALMEIDA MENDES (Oporto, 2004): 13/30, y del mismo: (Lisboa, 2005): 351/387.

16 FONSECA, 2002. FONSECA 2010. Y para Andalucía: FERNÁNDEZ CHAVES y PÉREZ GARCÍA, 2010, 5/34. FERNÁNDEZ CHAVES y PÉREZ GARCÍA, 2005, 123/133.

17 OTTE, 1996. LADERO QUESADA, 1989.

18 GIL (Londres, 1992): 40/56.

19 GARCÍA FIGUERAS (Sevilla, 1948): 1/41.
} 
El descubrimiento de América, la apertura de unas Indias para Castilla y la instalación de la Casa de la Contratación en Sevilla en 1503 redimensionaron el papel económico de Sevilla en una nueva dirección, precisamente en la época en que las cifras de esclavos africanos comercializados por los portugueses desde sus factorías hacia la Península Ibérica no dejaban de crecer a un ritmo vertiginoso, como han puesto de manifiesto los datos aportados por Antonio Almeida o Ivana Ebl. Fue precisamente el negocio esclavista que los portugueses ejercían de manera absolutamente protagonista gracias a su control de las zonas de aprovisionamiento en África (reconocido desde el punto de vista político en el Tratado de Alcaçovas de 1479) el que les permitió no sólo vender enormes cargamentos de esclavos negros en los puertos andaluces (desde Sanlúcar de Barrameda a SeviIla o Málaga), sino consolidar su posición en toda la región ${ }^{20}$ y comenzar a asentar en ella sus redes de distribución y comercialización enraizadas desde Lisboa y Portugal hasta Arguim, Cabo Verde, Guinea, el Congo y Santo Tomé. Fue así, gracias al negocio de importación de esclavos a aquella importante e internacional ciudad que era Sevilla en las décadas de tránsito entre el siglo XV y XVI, como los portugueses consiguieron hacerse un primer hueco en el complejo económico hispalense ${ }^{21}$. Otros negocios vinculados a su implantación atlántica, como el pastel de las Azores ${ }^{22}$, o su capacidad para la navegación, ayudaron también de forma importante a la consolidación de la presencia mercantil portuguesa en la SeviIla de la primera mitad del siglo XVI. A partir de Sevilla, las redes de comercialización de esclavos y de distribución del pastel portugués hacia los centros textiles del interior de Andalucía (desde Écija, Antequera y Córdoba hasta Málaga o Úbeda ${ }^{23}$ consolidaron su presencia en toda la región y contribuyeron de manera inequívoca a hacer cada vez más rentables sus negocios. Esta expansión mercantil portuguesa también se produjo hacia el norte de Europa, como prueba la existencia de la colonia lusa en Amberes ${ }^{24}$, donde penetraron al favor de su capacidad para aprovisionar la gran plaza europea con las especias que traían de Oriente. Sin embargo, si en relación con su expansión económica hacia el norte europeo los portugueses tejieron no sólo redes mercantiles sino también financieras, sostenidas por importantes mercaderes y financieros de origen judeoconver$\mathrm{so}^{25}$, hacia Sevilla y lo que esta representaba (no sólo la puerta del Mediterráneo sino la América española y el tráfico atlántico), su presencia económica durante las primeras décadas del Quinientos se limitó mucho más a lo estrictamente mercantil, manteniéndose la mayor parte de las transacciones financieras bajo el control de las grandes firmas italianas asentadas en el espacio comprendido entre

${ }^{20}$ Véanse, entre otros trabajos, los de LÓPEZ BELTRÁN y GONZÁLEZ ARÉVALO (Málaga, 2002): 309/338. LÓPEZ DE COCA CASTAÑER, 1989 1, 241/262.

21 FRANCO SILVA, 1984, 339/349.

22 OTTE, 2008.

${ }^{23}$ OTTE (Sevilla, 2003): 429/467. FERNÁNDEZ CHAVES y PÉREZ GARCÍA, R. M., en prensa.

24 GORIS, 1925.

25 Como se pone de manifiesto, por ejemplo, en las Lettres marchandes d'Anvers, recopiladas y publicadas en su día por V. Vázquez de Prada. 
el norte de Italia, Amberes y Lisboa-Sevilla. En el aspecto financiero y en relación con Sevilla, los portugueses trabajaron en una relación de estricta dependencia de las redes financieras italianas, especialmente los Affaitati, los Boti y otros ${ }^{26}$.

\section{LA TRATA NEGRERA EN TIEMPOS DE CARLOS I: ENTRE EL COMERCIO Y LA ESPECULACIÓN FINANCIERA}

La llegada de Carlos I a la Península Ibérica supuso de forma casi inmediata un potente empujón al desarrollo de la trata negrera hacia la América española. La subida al trono del nieto de Isabel y Fernando y su venida a Castilla produjo una inmediata activación del negocio esclavista hacia América, de la mano del interés que el entorno flamenco del joven monarca puso inmediatamente en el asunto ${ }^{27}$.

En el cuarto de siglo siguiente, hasta comienzos de los años cuarenta, los portugueses participaron en la trata que se estaba articulando gracias a que eran insustituibles debido a que controlaban las fuentes de abastecimiento de esclavos negroafricanos, tanto desde el punto de vista político como desde el dominio físico de las zonas de captura y la navegación hacia y desde ellas ${ }^{28}$. También participaban en la navegación, como pilotos y maestres de naos, también como marineros, o proporcionando directamente los barcos. Pero los niveles político (la Corte) y financieros del negocio, donde se podían obtener los grandes beneficios, quedaron casi siempre lejos de su alcance. En un primer momento son flamencos, y luego alemanes, quienes demuestran tener mayor capacidad de acceso a la Corte para recibir del Rey las licencias necesarias para llevar esclavos a las Indias. Sin embargo, para estos, carentes todavía de la necesaria infraestructura financiera y logística para entrar en el negocio negrero, la oportunidad de obtener ganancias se cifraba en la especulación, su reventa y traspaso a los sectores capitalistas de la propia Castilla, es decir, los genoveses y la burguesía mercantil de los grandes centros económicos del país (Burgos, Toledo y Sevilla, fundamentalmente). A comienzos de la década de 1530 los portugueses ocupaban todavía un lugar secundario entre las colonias de extranjeros asentadas en Sevilla. En la descripción de éstas que hace el cronista Luis de Peraza hacia 1535-1536, los portugueses se mencionan simplemente como una más entre las muchas existentes procedentes de los distintos reinos de la península ibérica y de la Cristiandad, siendo las que sobresalen por su importancia económica las de origen italiano, y muy especialmente los genoveses. Eso sí, Peraza no acaba esa descripción de los habitantes de la ciudad sin referirse a que en Sevilla «hay infinita multitud de negros y negras

${ }^{26}$ Sólo un botón de muestra: RAU (Lisboa, 1964/1965): 3/35.

27 RAMOS (Méjico, 1976): 7/10.

${ }^{28}$ La vertiente política de la gestión portuguesa de sus centros esclavistas, organizados fundamentalmente en torno a Cabo Verde mediante el sistema de contratos de arrendamiento, así como su imbricación en el sistema atlántico español a través de la exportación de los esclavos hacia la América española, ha sido explicada por FERRAZ TORRÃO, 2013, 93/106. 
de todas las partes de Etiopía y Guinea, de los quales nos servimos en Sevilla, y son traídos por la vía de Portugal $>{ }^{29}$. Es una cita especialmente significativa, pues fue gracias a su control del negocio exportador de esclavos negroafricanos como los portugueses acabaron penetrando en la economía de Sevilla. Pero la inicial desconexión existente entre aquellos (flamencos y alemanes) que acceden a la gracia del Rey en forma de licencias para exportar esclavos negros a América, con los portugueses, dificultó en los primeros años la propia trata, haciéndola mucho menos fructífera. Veamos algunos ejemplos de cómo se desarrollaron estos primeros grandes negocios esclavistas.

El caso de la famosa licencia para pasar 4.000 esclavos negros concedida en 1518 por el Rey Carlos I al flamenco Laurent de Gouvenot (o Gorrevod), gobernador de Bresa, resulta clarificador. La cédula real concediéndola es de Zaragoza de 18 de agosto de 1518, donde se encontraba la Corte $^{30}$. Gorrevod, a su vez, autorizó en octubre del mismo año a Juan López de Recalde, contador de la Casa de la Contratación, para que operase con la licencia y realizase los envíos de esclavos a las Indias ${ }^{31}$. Pero enseguida desistió de su intento de implicarse directamente en la trata negrera y en 12 de enero de 1519, ocho días después de la muerte del emperador Maximiliano, revendió por la suma de 25.000 ducados las licencias a una compañía genovesa que trabajaba en el ámbito de la propia Corte, formada por Adamo Vivaldi, Tomasso de Fornari y Compañía, y que incluía a Gaspare Centurione. Según Enrique Otte, socios principales de estos genoveses fueron el mercader toledano Hernán Vázquez, el burgalés Juan Fernández de Castro, y el sevillano Alonso Gutiérrez de Madrid, veinticuatro de Sevilla y contador mayor de la ciudad, en relaciones con los Centurione desde hacía mucho y que había sido también socio a su vez del propio Gorrevod. A pesar de las desavenencias habidas entre Fernández de Castro y los genoveses, así como del pleito puesto por Gorrevod contra el burgalés por falta del pago de las cuotas correspondientes a la venta, lo cierto es que a lo largo de la década de 1520 los genoveses fueron haciendo envíos de esclavos hacia las Indias, como el de 140 negros a Cuba en 1519 o el de 300 en 1526 , entre otros ${ }^{32}$. Pero junto a los cargamentos despachados, normalmente en navíos de terceros, los genoveses procedieron a la reventa de licencias ${ }^{33}$, generando un mercado de segunda mano en el que estas se encarecían paulatinamente para todos aquellos mercaderes ávidos de participar en la trata negrera pero que no tenían capacidad para obtener directamente del Rey las necesarias licencias; otra consecuencia de este fenómeno especulativo fue, finalmente, la efectiva limitación del número de esclavos navegados hacia las Indias a causa del altísi-

29 PERAZA, 1996, 70/71.

30 Archivo General de Indias (AGI): Contratación, leg. 5760, f. 17r. Véase también SCELLE, 1906 1, 141.

31 Ibidem, 149

32 OTTE, 2000, tomo VIII, docs. 988 y 1098.

${ }_{33}$ Por ejemplo, Catálogo de los fondos americanos del Archivo de Protocolos de Sevilla, Sevilla, 1990, tomo VII, doc. 1056. 
mo precio alcanzado por las licencias ${ }^{34}$. Las reventas sucesivas de licencias procedentes de los grandes lotes concedidos en 1518 prolongaron la vida útil de estas y permitieron participar en aquel negocio a diversos sujetos. Todavía en septiembre de 1529, el mercader burgalés Juan de la Torre, estante en Sevilla, otorgaba un poder a favor de Pedro Montero, estante en Lisboa, para que pudiese introducir en el puerto de Santo Domingo y en la isla de San Juan, 60 ó 70 esclavos negros, cediéndole para ello las licencias necesarias que tenía procedentes del gobernador de Bresa ${ }^{35}$. Y en 1530, el mercader toledano Hernán Vázquez, que a estas alturas ya era regidor de su ciudad, junto con el banquero genovés avecindado en Sevilla Agustín de Vivaldo, todavía negociaba con las sesenta licencias que le quedaban de las cien que obtuvieron del paquete de otras 400 licencias concedidas por el Rey en 1518 al difunto Marqués de Astor$\mathrm{ga}^{36}$, ultimando su traspaso a los importantes mercaderes judeoconversos sevillanos Fernando de Jerez y Juan Núñez ${ }^{37}$.

En los años siguientes los alemanes desplazaron a los flamencos en el entorno económico-cortesano del emperador. Como ha explicado Demetrio Ramos, la voluntad de penetración de los Welser en la propia empresa americana, más allá de operaciones financieras, fue muy temprana. Ya en 1525 se autorizaba a Lázaro Nurenberg, vecino de Sevilla, y a Jacome Comberger, a ir y contratar con las Indias como si fuesen naturales de los reinos de Castilla. De hecho, en cuanto pudieron, los famosos Enrique Ynger (o Ehinger) y Jerónimo Sayler compraron a Agustín Vivaldo y a Domingo de Forne 58 y 85 licencias respectivamente procedentes del paquete de Gorrevod, que todavía en 1534 coleaban $^{38}$. Así se llega al famoso asiento de negros concedido por la Monarquía por cédula de Burgos dada a 12 de febrero de 1528 a favor de los alemanes Ehinger y Sayler, factores de los Welser, para la introducción de 4.000 esclavos en Indias, negocio estrechamente vinculado al de las explotaciones mineras que el emperador quería promover en América con el apoyo de los Welser ${ }^{39}$. Los genoveses intuyeron enseguida el peligro que para su negocio podía significar un monopolio negrero en manos alemanas, por lo que pocos días después iniciaron negociaciones en la Corte ofreciendo al Rey una contraoferta que mejorase las condiciones ofrecidas por los Welser. $\mathrm{Si}$ estos se habían comprometido a pagar a la Hacienda real 20.000 ducados por las

\footnotetext{
34 A este fenómeno especulativo ya se refirió Demetrio Ramos: (Méjico, 1976): 9/10 y 31.

35 Archivo Histórico Provincial de Sevilla (AHPSe): Protocolos Notariales de Sevilla (PNS), leg. 3279 , f. 480. Sevilla, 28-IX-1529. Cf. Catálogo de los fondos americanos del Archivo de Protocolos de Sevilla. Sevilla, 2004, tomo IX, doc. 1042.

${ }^{36}$ La cédula de 27-IX-1518 a favor del marqués de Astorga en AGI: Contratación, leg. 5760, f. 7r.

37 En concreto, Hernán Vázquez y Agustín de Bivaldo prometían a los mercaderes Fernando de Jerez y Juan Júñez la quieta y pacífica posesión de sesenta piezas de esclavos con sus respectivas licencias para pasarlos a las Indias, una vez que estos abonasen 71 ducados al tesorero de la Casa de la Contratación o a Juan de Eguíbar, oficial de dicha Casa, conforme al contrato de venta de dichos esclavos. AHPSe: PNS, leg. 38, f. 163v, 16-IX-1530. Cf. Catálogo..., tomo IX, doc. 1427. También AGI: Contratación, leg. 5760, f. 11v.

38 AGI: Contratación, leg. 5760.

39 RAMOS (Méjico, 1976): 21/63.
} 
4.000 licencias, el genovés Pedro Benito de Basiñana intentó arrebatarles la concesión subiendo la cantidad a pagar hasta 24.000 ducados ${ }^{40}$. Basiñana comerciaba desde hacía algunos años con América desde Sevilla, y se había introducido en el tráfico de esclavos, al menos desde los tiempos iniciales de la explotación de la licencia de Gorrevod ${ }^{41}$; en los años siguientes trabajó codo con codo con distintos portugueses para cargar esclavos en Santo Tomé y Cabo Verde para enviar esclavos a las Indias, utilizando a veces navíos portugueses ${ }^{42}$. Su relación con las redes negreras portuguesas le permitió continuar participando en la trata negrera de manera importante, como cuando obtuvo del bachiller Álvaro de Castro, deán de la Concepción de la isla Española, la mitad de la licencia que este había recibido del Rey en 8-VII-1525 autorizándole a pasar 200 esclavos negros de Guinea a las Indias ${ }^{43}$. A pesar de que la pretensión de Basiñana contra los alemanes no tuvo efecto, lo cierto es que no por ello dejó de participar en el gran negocio esclavista del Atlántico.

La gran licencia concedida a los alemanes tampoco produjo que la técnica del deslizamiento de concesiones, como la llamó Ramos ${ }^{44}$, dejase de funcionar en la Sevilla de la época. De hecho, lo que se produce en la Sevilla de aquellos años es un concurso multinacional tanto en el tráfico especulativo de licencias como en la propia trata negrera. Así, ya antes de la concesión del asiento con Ehinger y Sayler, el alemán Lázaro Nuremberg se ha introducido en el entramado mercantil atlántico de la ciudad y participa, parece incluso que ilegalmente (sin licencias), en la propia trata negrera ${ }^{45}$. Los mismos Ehinger y Sayler, que obtuvieron en 1532 una prórroga para poder navegar las licencias que todavía no habían empleado, trabajaron directamente con mercaderes portugueses, que les proporcionaron no sólo miles de esclavos, sino que los introdujeron, legal o ilegalmente, directamente desde Cabo Verde o Lisboa en Santo Domingo y las Antillas ${ }^{46}$. Por otra parte, el consorcio entre alemanes y portugueses no impidió que los otros grupos interesados en la trata pudieran continuar participando en él. Durante los años siguientes, el propio Basiñana continuó participando en el envío de esclavos, a veces ponien-

\footnotetext{
40 AHPSe: PNS, leg. 31, f. 489. Sevilla, 27-II-1528. Cf. Catálogo..., tomo IX, doc. 604.

41 En 21 de mayo de 1519 cargó cinco esclavos en la nao de Martín de Aguirre, en virtud de la parte correspondiente de la licencia de Gorrevod. AGl: Contratación, leg. 5760, f. 21v.

42 En 1526, por ejemplo, Basiñana, que aparece como mercader genovés estante en Sevilla, otorgaba poder al portugués Juan Rodríguez, vecino de Lisboa, para que fuera de piloto y capitán de un navío que iría a Santo Tomé y a Cabo Verde para comprar 20 esclavos, hombres y mujeres, que deberían ser llevados después al Puerto de Plata, en virtud del privilegio real que tenía para ello (Catálogo..., IX, doc. 73). A comienzos de 1527 Basiñana disfrutaba de una licencia para comprar una nao portuguesa, que además podría llevar cuatro portugueses entre la tripulación, que podría dirigirse a Guinea a comprar esclavos para pasarlos a América (Catálogo..., V, doc. 1246).

43 RAMOS (Méjico, 1976): 43; Catálogo..., tomo IX, doc. 257.

44 RAMOS (Méjico, 1976): 43.

45 Así parece indicarlo un documento de 1528 por el que el mercader sevillano Juan Martínez y el catalán Felipe Ribas, se obligaban a sacar en paz y a salvo a Lázaro Nuremberg, vecino de Sevilla, de la fianza de 200 ducados que había prestado al mercader Pedro Márquez, que había llevado esclavos a las Indias sin licencia. AHPSe: PNS, leg. 31, f. 85. Sevilla, 10-I-1528. Cf. Catálogo..., tomo IX, doc. 504.

46 RAMOS (Méjico, 1976): 71/76.
} 
do en ejecución las licencias concedidas a otros ${ }^{47}$, y siguió participando en la reventa de licencias ${ }^{48}$. De hecho, en el mercado de la reventa acabó adquiriendo incluso licencias procedentes de los paquetes de Ehinger-Sayler ${ }^{49}$, o consiguiendo él mismo las propias directamente del Rey ${ }^{50}$.

Desde una fecha temprana, y que todavía no podemos precisar con exactitud, fue una familia de judeoconversos andaluces, los Torres ${ }^{51}$, la que jugó un papel crucial en la difícil tarea de conectar el mercado portugués de aprovisionamiento de esclavos a partir de las factorías africanas y el acceso al mismo a través del contacto con la Corte portuguesa, con el sistema castellano de licencias de esclavos y el entramado mercantil sevillano. En efecto, los Torres tejieron una eficaz red entre Lisboa y Sevilla, aunque su ámbito de operaciones era en realidad mucho más amplio, pues se extendía desde las propias Indias hasta Roma, en cuya corte pontificia se establecieron sólidamente. No es este el momento de entrar en detalles, pues el tema es amplísimo y sobre el mismo preparamos un estudio monográfico. Aquí nos interesa sólo que ya en 1523 Diego y Alonso de Torres aparecen en Lisboa recibiendo de Juan Fernández de Castro (que actúa a través de Fernando de Castro) un poder que les autorizaba, junto con el mercader burgalés asentado en Sevilla Juan de Polanco Maluenda, a enviar 200 piezas de esclavos negros en virtud de la licencia concedida originariamente al gobernador de Bresa ${ }^{52}$. De la consolidación de la posición de los dos hermanos Torres en Lisboa habla el hecho de que Alonso (o Alfonso) de Torres llegase a ser fidalgo de la Orden de Cristo y factor del Rey de Portugal. Alonso, además, se convirtió en una pieza clave en la organización del aprovisionamiento atlántico de los cargamentos de esclavos, al convertirse en rendeiro de los esclavos de los ríos de Guinea entre 1529-1531 y en 1536-1542, además de ser oficial de la Casa da Mina ${ }^{53}$. Diego, por su parte, actuará entre Lisboa y Sevilla. Y en Sevilla, otro hermano, Gaspar de Torres, llegará a jurado de la ciudad. De hecho, los Torres consiguieron ganar licencias de los principales lotes otorgados por la Corona, no sólo en el de Gorrevod, como vimos. Así por ejemplo, en 1530 Alonso de Torres, que aparece ya como factor del Rey de Portugal, y en unión con el mercader sevillano Alonso Núñez, tenía 100 licencias procedentes de Sayler y Ehinger, que estos habían traspasado al secretario real

\footnotetext{
47 Por ejemplo, en 1528 Basiñana recibió poder de Pedro de Samanos, estante en Sevilla, para pasar a Nueva España los dos esclavos negros para los que el Emperador le había concedido licencia. AHPSe: PNS, leg. 31, f. 252v. Sevilla, 30-I-1528. Catálogo..., tomo IX, doc. 541.

${ }^{48}$ Catálogo..., tomo IX, docs. 1057-1058.

49 Una cédula de 21 de junio de 1534 hizo merced a Ehinger y Sayler de otras 800 licencias. Estos pasaron un centenar a Alonso Román, que a su vez traspasó 33 de ellas a Basiñana (AGl: Contratación, leg. 5760).

50 Por ejemplo, una cédula dada en Toledo en 24 de mayo de 1534 le otorgó licencia para pasar 50 esclavos negros a Indias (AGI: Contratación, leg. 5760).

${ }^{51}$ Sobre los orígenes de esta familia, véanse los excelentes trabajos de la profesora María Teresa López Beltrán, especialmente: LÓPEZ BELTRÁN, 2002, 397/419. No eran portugueses, como se sugiere en MATEUS VENTURA, 1999, 38/42, y se repite por otros autores.

52 AHPSe: PNS, leg. 3254, f. 91v, 19-II-1523. Cf. Catálogo..., tomo VIII, doc. 1188.

53 FERNÁNDEZ CHAVES y PÉREZ GARCÍA, 2011, 231, a partir de FERRAZ TORRAO, 1999.
} 
Juan Vázquez de Molina, y este a su vez a ellos, quienes vendieron al mercader Sancho Caballero la parte correspondiente para pasar a las Indias 50 piezas de esclavos ${ }^{54}$. Unos meses más tarde, en marzo de 1531, volvemos a documentar a Alfonso de Torres, vecino de Lisboa y Comendador de la Orden de Cristo, vendiendo mancomunadamente y a través del mercader sevillano Alfonso Núñez a los también sevillanos Luis Fernández de Alfaro y a su hijo Juan de Alfaro, 100 esclavos negros que se habrían de adquirir en Arguim, Guinea y Cabo Verde y que se deberían enviar al puerto de Santo Domingo ${ }^{55}$. En Santo Domingo, por su parte, se encontraba otro hermano, Melchor de Torres, que llegó a ser junto con Álvaro Caballero uno de los hombres más poderosos y ricos de la isla, poseyendo tres ingenios de azúcar en los que trabajaban más de 400 esclavos, aparte de trapiches, haciendas y ganado ${ }^{56}$. Desde allí Melchor de Torres dirigía los negocios familiares en América. Así, los Torres, se fueron convirtiendo en la pieza clave que conectaba el mercado portugués con el sistema de licencias castellano y el entramado mercantil que pivotaba en torno a Sevilla, estableciendo importantes relaciones económicas con las grandes familias sevillanas, algunas de ellas judeoconversas, que participaron en la trata negrera en esta época, como los Caballero, con quienes compartían también una posición claramente dominante en La Española. De hecho, no deja de ser significativo que en una carta de 8 de marzo de 1529 , uno de los Caballero se quejara de cómo el «estanco de negros» capitulado «con los alemanes» habia encarecido rápidamente el precio de los esclavos en La Española ${ }^{57}$, si bien él y otros superaron aquella coyuntura negociando con los Torres. La alianza entre los Torres y los Caballero se expresa, por ejemplo, en la petición que en 2 de noviembre de 1536 realizaron conjuntamente Gaspar de Torres y Alonso Caballero solicitando al Rey la concesión del derecho a pasar a las Indias 4.000 esclavos negros por un precio de 26.000 ducados a pagar entre 1536 y 1537, así como a realizar un préstamo por otros 14.000 ducados ${ }^{58}$. Hasta donde sabemos, no parece que la Corona aceptase este ofrecimiento. Para aquellos años, algunos portugueses, cercanos a la Corte, comenzaban a penetrar en el ámbito de la obtención de licencias por parte de la Corona castellana, y en ese proceso los Torres también estuvieron presentes. Es significativo que cuando el mercader portugués Diego Martínez obtuvo licencia en 1535 para pasar 1.000 esclavos varones y hembras a las Indias ${ }^{59}$, la traspasó a Melchor Letón (o Leitão), caballero de la Casa del Infante Don Luis, quien por su parte las vendió a Gaspar de Torres, el cual a su vez, negociaba con ellas unos meses más tarde, vendiéndolas tanto individualmente ${ }^{60}$ como en lotes medianos (una licencia para pasar 40

54 Catálogo..., tomo VI, doc. 1518. Sevilla, 16-XI-1530.

55 AHPSe: PNS, leg. 1532, f. 225r-228r. Sevilla, 31-III-1531.

56 RODRÍGUEZ MOREL (Sevilla, 1992):101/102.

57 RAMOS (Méjico, 1976): 63.

58 AGI: Indiferente, leg. 2795.

59 La cédula es de Guadalajara, de 4-III-1535 (AGI: Contratación, leg. 5760).

60 Como la licencia de un esclavo que vendió a Jácome de Mallea, estante en Sevilla. AHPSe: PNS, leg. 10554, f. 441r. Sevilla, 17-XI-1535. 
esclavos las vendió al importante mercader sevillano Melchor de Carrión) o grandes, ya que vendió el derecho de pasar 600 esclavos a Alonso Caballero, quien a su vez revendió también una parte a Carrión ${ }^{61}$. Es importante comprender que esta colaboración entre los Torres y negociantes portugueses no respondía a contactos puntuales, sino a sólidas ententes extendidas tanto tipológica como geográficamente: por ejemplo, poco antes, en 1533, Diego de Torres ya había trabajado con Diego Martínez (Diogo Martines) en relación con el tráfico de las especias hacia Amberes ${ }^{62}$.

En los años siguientes, la red de los Torres siguió subiendo posiciones en el negocio de la trata negrera atlántica. La historiografía, desde Scelle ${ }^{63}$ hasta Mateus Ventura, ha venido señalando la importancia del «asiento» firmado con los Torres en 1541 para pasar esclavos a Honduras, si bien no se ha contextualizado adecuadamente este contrato ni el marco de la propia familia ni en el de su posición económica en el eje Lisboa-Sevilla-Indias. Ante la necesidad de mano de obra para trabajar en la minería del oro de Honduras, el cabildo de Trujillo y los colonos de la zona llevaban al menos desde 1530 pidiendo a la Corona que les permitiese importar esclavos negros que complementasen o sustituyesen el trabajo indígena, cada vez más escaso tanto por motivos demográficos como por las prohibiciones para hacer trabajar a los indios en las minas, que se promulgan en Honduras en 1539 de la mano del licenciado Cristóbal de Pedraza, primero protector de los indios de la Gobernación de Higueras y Cabo de Honduras desde 1537, y luego obispo de Honduras. Estos hechos condujeron a la Corona a autorizar a que Pedraza, de vuelta en España, negociase y firmase con Alonso y Diego de Torres el envío a Honduras de 300 esclavos negros, de los cuales la tercera parte serían mujeres, en magníficas condiciones económicas para los hermanos tratantes. El acuerdo se firmó en 1541. Al año siguiente llegó un cargamento de 180 esclavos enviado por los Torres; también en 1542, en noviembre, llegó al puerto de Trujillo otra carabela portuguesa con otros 175 esclavos, si bien setenta de ellos venían ilegalmente, habiendo sido embarcados desde Santo Domingo sin las necesarias licencias; no es casualidad que el remitente de los esclavos no fuera sino Melchor de Torres. Es digno de reseñar que el comienzo de la introducción masiva de esclavos negros en Honduras abra el periodo más esplendoroso de la extracción de oro en ella: piénsese que sólo en la década de 1540 se extrajeron de la región más de 1.800 kilogramos de oro, el $38,16 \%$ del que produjo en todo el siglo, y el 7,26\% del total americano ${ }^{64}$. Ello explica que la relación de los Torres con Honduras no se limitase a la introducción de esclavos, sino que se extendiese a otros negocios y a la colaboración con otros ricos e importantes mercaderes, como los Almonte, en los años siguientes ${ }^{65}$. Comenzaban

61 AGl: Contratación, leg. 5760.

${ }^{62}$ RAU (Lisboa, 1964/1965): 5.

63 SCELLE, 1906 1, 191/193.

64 GÓMEZ ZÚÑIGA, 2012. La cédula real dada en Talavera a 16 de mayo de 1541 con las condiciones del contrato con los Torres en AGI, Contratación, leg. 5760.

65 Véase, por ejemplo, Catálogo..., IV, docs. 902, 940 y 1428, de los años 1549 y 1551. 
los años de oro para los Torres, que nunca perdieron de vista que su gran negocio giraba en torno a la esclavitud. Los datos sobre licencias de esclavos concedidas en el periodo 1544-1550 sacados a la luz por Esteban Mira Caballos lo ponen de manifiesto. En esos años, Gaspar de Torres lidera de forma clara la lista de aquellos que consiguen licencias, con un total de 2.032 , el $15,74 \%$ del total. Tras él, son una serie de principalísimas familias sevillanas, representadas por los hermanos Gonzalo y Gaspar Jorge, Hernando de Jerez y sus herederos, Diego Caballero, Melchor de Carrión, Francisco Núñez Pérez o Rodrigo Bazo, los que lucran otras más de 4.350 licencias, otro $33,69 \%$, poniendo de manifiesto el peso que el capital sevillano jugaba de forma directa en la gestión política y financiera, además de estrictamente mercantil, de la trata negrera atlántica ${ }^{66}$. Según el estudio de Ferraz Torrão para los años 1541-1546, del centenar de licencias concedidas en esos años, sólo una se otorgó directamente a un portugués, Lourenço Álvares, el 1 de mayo de 1543 para introducir 100 esclavos en las Indias de Castilla. Ello prueba que los portugueses seguían esencialmente alejados del acceso al nivel político de gestión castellana de la trata. Sin embargo, los grandes beneficiarios de licencias y mercaderes sevillanos trabajaban con agentes, pilotos y barcos portugueses, donde se cargaban buena parte de los esclavos, dominando los lusos claramente esta parte de la trata negrera $^{67}$. Sobre aquel trasfondo de dos imperios atlánticos obligados a compenetrarse y estrechamente imbricados, a finales de los años cuarenta y comienzos de los cincuenta, los Torres seguían enviando esclavos desde las posesiones portugueses hacia Nueva España o Santo Domingo, y regresando con azúcar o cueros a Sevilla ${ }^{68}$. Para esta época próxima a la mitad de la centuria, la penetración portuguesa en la ciudad de Sevilla había avanzado poderosamente, a pesar de que nuevamente, en 1552, cuando se concede la gran y polémica merced para pasar 23.000 esclavos a Indias, los portugueses volvieron a quedar fuera de la primera línea del negocio, quedando este en manos de financieros castellanos y genoveses ${ }^{69}$.

\section{LA CONSOLIDACIÓN PORTUGUESA DESDE MEDIADOS DEL QUINIENTOS}

Entre los años cuarenta y cincuenta del siglo XVI la documentación notarial sevillana da fe de una actividad económica protagonizada por portugueses que va más allá de la gran trata negrera o su participación en la logística naval de la expansión castellana. Existían al menos dos perfiles claros de participación en el entramado de negocios sevillano. El primero es muy dependiente de las relaciones cortesanas entre Castilla y Portugal, reforzado por el casamiento del príncipe Feli-

66 MIRA CABALLOS (Madrid, 1994): 273/297.

67 FERRAZ TORRÃO, 2002, 203/222.

68 AGI: Justicia, leg. 831, pieza 5; Catálogos..., IV, doc. 1207.

69 OTTE, 2008, 271 y ss. El texto del asiento está publicado en FERNÁNDEZ ÁLVAREZ, 1977, 3, $463 / 466$. 
pe con la infanta María entre 1543 y 1545 , y el posterior enlace de la hermana del primero, Juana, con el príncipe Juan Manuel, que duró desde 1552 a 1554. Este perfil está protagonizado por hombres de negocios que tienen parte de la gestión de los intereses económicos de la corte portuguesa en Sevilla y que obtienen una posición de ventaja gracias a esta gestión. Ya hemos visto como los Torres están cercanos a la corte de João III y tienen acceso a los contratos de Cabo Verde y al mercado de las licencias de esclavos. Junto a estos grandes hombres de negocios aparecen importantes mercaderes como los hermanos Blas Reynel y Duarte Rodríguez, quienes desarrollan una gran actividad desde finales de la década de los cuarenta hasta 1555. Blas Reynel radicaba en Sevilla como «estante» mientras su hermano Duarte viajaba entre esta ciudad y Lisboa representando sus intereses mutuos; ambos eran hijos de los vecinos de Tavira Manuel Gomes y Blanca Rodriguez, añadiendo en alguna ocasión Blas Reynel a su apellido el de «Lima» ${ }^{70}$, por lo que quizá pudo estar emparentado con los exitosos comerciantes y tratantes en esclavos que se asentarán en la ciudad a finales de siglo ${ }^{71}$. Blas Reynel fue descrito por Enrique Otte como un "gran mercader del comercio internacional» en la Sevilla de las décadas centrales del siglo XVI, y se dedicaba entre otros negocios a la importación de textil de Flandes a la ciudad de Sevilla, por lo que parece que Reynel tenía importantes contactos con la factoría portuguesa de Amberes. De esta manera en el bienio de 1549-1550 realizó ventas de diferentes textiles de dicha procedencia por valor de $353.507 \mathrm{mrs}^{72}$, trayendo además cera de dicha región ${ }^{73}$. Reynel trataba también con mercaderes ingleses, la colonia extranjera más importante en aquellos años en la ciudad ${ }^{74}$. Uno de los socios de Reynel en Lisboa, Juan Fernández Albito, le enviaba mercancías con ingleses venidos de «Beomares» y Bristol, quienes cobraban de Reynel presentándole cédulas de cambio enviadas por Albito ${ }^{75}$. Reynel vendía estas mercancías a comerciantes sevillanos que muy

${ }^{70}$ AHPSe: PNS, leg. 9172, f. 1066r (23-IV-1554), y leg. 9172, f. 1072r, 25-IV-1554.

71 OTTE y RUIZ-BURRUECOS (Santander, 1963): 3/40, en concreto 18/31. KELLENBENZ, 1958, 371 y ss., según el artículo de E. Otte previamente citado.

72 El alemán y vecino en la collación de Santa María, Lázaro Nuremberger, se obligaba a pagarle en un año, $62.310 \mathrm{mrs}$. por 12 piezas de holandas finas que le compró en 18-XI-1549. Cf. KELLENBENZ y ROLF, 2001, 288. Ese mismo año de 1549 distintos compradores le debían la suma total de 235.722 mrs., obtenidos a cambio de 26 piezas de estameña, 5 piezas de olanda, 1 pieza de manteles, 26 piezas de tornasoles, y 4 piezas de fustanes, 11 piezas de fustanes prietos, 17 piezas de anascote, y un barril de conserva. AHPSe: PNS, leg. 9164, f. 58r-v, 496r-v, 666r-v, documentos de 5-I-1549, 9-III-1549 y 29-III-1549. El año siguiente vendía doce piezas de holanda al joyero y vecino de Sevilla Miguel Martín, por valor de 55.475 mrs. a 1.250 mrs. la libra (AHPSe: PNS, leg. 9166, f. 90r. 11-I-1550).

${ }^{73}$ OTTE, 2008, 189. Vendió 200 quintales de cera de Flandes a 15 ducados el quintal y a tres candeleros 58 arrobas y $17 \frac{1 / 2}{2}$ libras por $88.000 \mathrm{mrs}$.

74 OTTE, 2008, 276 y ss.

75 Así en 1550 pagaba al inglés Francisco Reynol «natural de Beomares», 100 ducados de oro, que fueron pagados previa entrega de una cédula de cambio dirigida desde Lisboa por Juan Fernández Albito, recibida en el banco de Pedro Juan Leardo, pagando del mismo modo 113.500 mrs. ducados de oro al inglés vecino de «Beomares», Elías Estofel, y abonando directamente 25 ducados a Duarte Estanfazter, vecino de Bristol, como parte de dos cédulas de cambio que había de abonar por valor de 175 ducados enviadas por Albito desde Lisboa. AHPSe: PNS, leg. 9167, f. 494r, 6-XI-1550 y f. 518r 10-XI-1550, y f. 528r, 12-XI-1550. 
probablemente las reexpedían hacia América. La fuerte posición que alcanzara en tan poco tiempo le llevó a ser un hombre de confianza de varios mercaderes portugueses en la ciudad, recibiendo mercancías desde América en su nombre ${ }^{76}$, y haciendo de fiador de algunos de ellos.

Buena parte de su preponderancia económica se debía a que su actividad de mercader se complementaba con su actividad de giro de letras de cambio para Valencia, en la que descolló en la primera mitad de la década de los años cincuenta, donde enviaba las cédulas de cambio a nombre de Juan Antonio de Reynaldo de $\mathrm{Adda}^{77}$, adelantando el dinero a quienes se lo solicitaban, y ganando con el diferencial de cambios. Así, sólo en el primer semestre de 1554 giró catorce letras de cambio para Valencia adelantando el dinero por cerca de 7.500 ducados ${ }^{78}$. Es muy posible que la posición de Reynel en Sevilla dependiese no sólo de este banquero milanés, sino también de la poderosa casa de los Affaitatti o «Lafetás» afincada en Lisboa y asociada a los Giraldi, con los que negociaban sobre los contratos de la pimienta y otras mercancías, y realizaban importantes operaciones financieras ${ }^{79}$. Los Affaitatti eran según Otte «los dueños de la letra de cambio en Sevilla»80. Cabe pensar que Reynel funcionase en colaboración con ellos, pues cuando desaparece de la escena hispalense en 1555 en seguida es sustituido por los Affaitatti. Que Reynel fuera un hombre de confianza de los Affaitatti en la ciudad lo atestigua la entrega por parte de aquel en 1552 a Luis Guardi, estante en Lisboa, de 10.804.885 réis por mano del tesorero de la Casa da India Juan Gómez. Guardi a su vez los remitió previa orden de Reynel a Juan Bautista de Affaitatti y a Nicolás Guardi para que éstos los utilizaran para invertir en la feria de octubre de Medina del Campo. Con los beneficios Reynel debía obtener 8.507.916 mrs. que habían de serle ingresados en los bancos sevillanos de Alonso \& Pedro de Espinosa y Pedro de Morga, para que se sirviera de ellos el hermano de Reynel, Duarte Rodríguez. Esta entrega quedaba en manos del hombre de los Affaitatti en Sevilla, el milanés Andrea de San Julián ${ }^{81}$.

${ }^{76}$ En 21-XI-1551 su procurador Juan Suarez, vecino de Tavira y estante en Cádiz se encargaba de cobrar al maestre Pedro Meléndez 530 cueros que iban registrados por Antonio de Sequeira y Simón Rodríguez. Catálogo..., vol. IV, págs. 402-403.

77 Reynaldo había obtenido de Carlos V junto con otros comerciantes de Milán y Lucca un salvoconducto para comerciar con los territorios de Aragón, Valencia, Cataluña, Rosellón y Cerdeña en 1542, véase VARGAS-ZÚÑIGA y CUARTERO, 1950, 454 (Monzón, 9-X-1542).

78 No se olvide que Valencia constituye uno de los puntos esenciales del tráfico monetario hacia Italia y de hecho fue protagonista en el número de letras giradas durante las primeras décadas del siglo XVI, cf. OTTE, 1978, 100/102 y 109. Sobre la importancia de Valencia como plaza bancaria para otras colonias italianas como la genovesa, IGUAL LUIS (Valencia, 1992): 79/116.. También, PASTORINO, 2011, $219 / 249$.

79 Sobre estos, RAU (Lisboa, 1964/1965): 3/35.

80 Ofrece breves noticias sobre sus actividades, OTTE, 2008, 302. Tuvieron su primera aparición en 1516 en Sevilla y según Otte no reaparecen hasta 1546 en la ciudad.

${ }^{81}$ AHPSe: PNS, leg. 9172, f. 2040. Es normal esta vinculación con los Affaitatti, habida cuenta de que esta casa de crédito tenía fuertes relaciones con la colonia portuguesa presente en Lisboa así como también a través de sus préstamos con Carlos V y Felipe II, aunque entrarían en crisis precisamente por los muchos impagos carolinos y de Felipe II hacia 1577, cf. GORIS, 1925, 396/398. 
Blas Reynel abandonaría la ciudad en 1555 liquidando todas sus deudas y negocios, tras haber formado una compañía comercial basada en Lisboa con su hermano y un socio llamado Juan Fernández de León. Su vuelta a la capital lusa se debía además a su matrimonio con la hija de uno de los médicos de João III, Maestre Pedro, señal esta de su fuerte vinculación con la corte portuguesa, que debía estar basada en las relaciones de dependencia económica de sus miembros con el crédito proporcionado por los Affaittati y otras casas italianas en Lisboa, así como también a la propia corona castellana, con la que estos banqueros suscribieron un préstamo de 46.500 escudos en letras sobre Amberes en enero de $1556^{82}$.

Como vemos para mediados de siglo la presencia portuguesa en Sevilla era ya muy importante, y la percepción que existía sobre ellos se había transformado sustancialmente. En el contexto de la fase de depresión económica de 1554-1559, Chaunu se refiere al brote de xenofobia contra los portugueses, denunciados en 1558 de ser los enemigos del Monopolio sevillano ${ }^{83}$. Ese mismo año, Felipe II instó varias veces desde los Países Bajos a la Regente para que estableciera aduanas en la frontera de Portugal. Las aduanas fueron establecidas el 30 de enero de 1559, con la misión de cobrar el $10 \%$ del valor de lo que pasare por ellas; la medida se justificaba en base a las necesidades de la Hacienda real y al hecho de que Portugal sí cobrase derechos por las mercancías que entraban en él a través de la frontera ${ }^{84}$. Pero la política de la Monarquía no dejaba de ser, en el fondo, contradictoria, pues era precisamente la cada vez mayor capacidad para actuar en el ámbito de la Corte que demostraban los portugueses una de las claves de su éxito.

Esta relación «fuerte» con la Corte aparece también en el caso de uno de los grandes negreros y comerciantes lisboetas de mediados del siglo XVI, Manuel Caldeira ${ }^{85}$. Caldeira estará presente en las abdicaciones de Bruselas y fue uno de los prestamistas de Carlos V y su hijo, firmando con ellos en Bruselas un asiento por valor de 55.000 ducados el 20 de enero de $1556^{86}$. A cambio de sus préstamos, el Rey concedió a Caldeira ese mismo año una licencia para pasar a Indias 2.000 esclavos, que fueron enviados en distintos momentos a América. Junto con su cuñado y suegro, Bento Rodrigues, y su otro socio Diogo do Castro do Rio, participará en el tráfico de esclavos, azúcar y paños, siendo ambos caballeros fidalgos de la Casa del Rey, y Caldeira también caballero de la Orden de Cristo ${ }^{87}$ Recientemente ha sido señalado que Caldeira no pudo haber obtenido el primer asiento de esclavos concedido a un portugués si no fuese porque junto a sus socios fue «recomendado» por João III, influencia de la que se valieron previamente

82 CARANDE, 1977 II, 252/253. Valladolid, 8-I-1556.

83 CHAUNU, 1959, VIII/2/1, 347.

84 ULLOA, 1977, 253/254.

85 Sobre su figura y familia, FERRAZ TORRÃO, 2011, 43/63.

86 CARANDE, 1977, 252/253.

87 MATEUS VENTURA, 1999, 90/91. El texto del asiento con Manuel Caldeira para pasar 2.000 esclavos a las Indias de Castilla, firmado en Amberes en 2-III-1556, ha sido publicado en ibidem, 141/143. 
para arrendar las rentas de Santo Tomé y Cabo Verde al rey luso, con cuyo control esperaban poder suministrar en buenas condiciones los esclavos correspondientes a las 2.000 licencias que se les concedieron ${ }^{88}$. Caldeira y Bento Rodrigues tuvieron varios factores en Sevilla como Melchor de Vega o el portugués Manuel Enriques, aunque finalmente el hombre de confianza de Caldeira en Sevilla será en la década de 1560 el portugués Bento Vaez ${ }^{89}$. Hubo otros hombres en Sevilla como Luis Lobo que actuarían en nombre de Bento Rodrigues y de su hijo Manuel Caldeira o moço (sobrino del mercader homónimo que aquí estudiamos) en el reparto de los distintos negocios con el representante de la sociedad Affaitatti \& Giraldi en Sevilla, Andrea de San Julián ${ }^{90}$. Pero de entre todos ellos acabaría descollando por su actividad Bento Vaez, quien acabaría independizándose de Caldeira y convirtiéndose en uno de los más importantes miembros de la colonia portuguesa en Sevilla, protagonizando buena parte de los envíos de esclavos a América durante los años 60 y 70 del siglo ${ }^{91}$. También se dedicó a la importación de textil de buena calidad y de otras mercancías tanto para su consumo en Sevilla como para su envío a América, así como a los préstamos, envíos y recepción de dinero y mercancías a través de letras de cambio entre Medina del Campo, Sevilla y Lisboa. Vaez debía ser un hombre solvente a su llegada a la ciudad hacia 1553, coincidiendo con Blas Reinel, quien a su vuelta a Lisboa en 1555 confiaría en él para que representase sus intereses y liquidase sus negocios. Bento Vaez se afincó en Sevilla y formó una familia que se benefició de la gran fortuna amasada en algo más de veinte años y que se perdió en la bancarrota de 1575 y las confiscaciones subsiguientes, cuyos efectos se vieron agravados por la deserción de sus factores en las Indias con buena parte de sus últimas ganancias. Pese a todo ello, fue llamado por Felipe II en 1580, seguramente porque era considerado como un interlocutor valioso ante las perspectivas que se ofrecían al rey prudente ante la cuestión sucesoria portuguesa, pero fallecería en la Corte en aquel año ${ }^{92}$.

Por debajo de estos comerciantes que tienen una estrecha relación con las cortes de los Habsburgo y Avis, que colaboran con y trabajan para y dependen de los grandes financieros italianos (genoveses, milaneses o florentinos) y que participan de los grandes negocios que vertebran el imperio portugués, se encuentran los comerciantes que no participan del negocio financiero pero cuya actividad constituía un elemento vehicular entre los espacios atlántico-insulares ibéricos y la Península, hasta ahora poco atendidos por la historiografía. En su obra fundamental para entender el gran capitalismo comercial hispalense del siglo XVI, Enrique Otte no destacaba la importancia de los portugueses en la primera mitad del siglo, señalando que «con la excepción de su intervención del pastel de las Azo-

88 FERRAZ TORRÃO, 2013, 46/47. Las rentas de Cabo Verde fueron arrendadas por Rodrigues entre 1556 y 1562, FERRAZ TORRÃO, 2013, 93/106, aquí p. 104.

89 MATEUS VENTURA, 1999, 86/87 y 100/102.

90 AHPSe: PNS, leg. 9174, f. 1071r, año 1555.

91 FERNÁNDEZ CHAVES y PÉREZ GARCÍA, 2010, 24-25.

92 FERNÁNDEZ CHAVES y PÉREZ GARCÍA, «La trata negrera...». En prensa. 
res destacan poco», aunque cuenta hasta 63 comerciantes lusos, indica que «no aparecen mercaderes portugueses cristianos-nuevos, que, como se sabe, a fines del siglo XVI destacan mucho y son los dueños de la trata de esclavos negros» ${ }^{93}$.

Es precisamente la importación de pastel uno de los elementos clave en el desarrollo de la actividad económica de estos comerciantes portugueses de segundo nivel, muy activos en las décadas centrales del siglo, como Andrés López. Declarado como vecino de la ciudad ${ }^{94}$, vivía en unas «casas de morada» en el Alcázar viejo, en el corral de Jerez ${ }^{95}$, realizaba tratos que servían para abastecer las Azores y Madeira, de sal ${ }^{96}$, trigo ${ }^{97}$ y aceite ${ }^{98}$, al tiempo que utilizaba los productos allí cultivados y los que ofrecía el riquísimo mercado lisboeta, fundamentalmente especias ${ }^{99}$, como la canela ${ }^{100}$ y otros productos culinarios como la almendra ${ }^{101}$, para comerciar en Sevilla y en otras zonas como Granada ${ }^{102}$. El papel de Sevilla como centro productor de textiles y como espacio esencial de servicios en toda la región bética proporcionaba a Andrés López una gran demanda de productos tintóreos, algunos producidos en las Azores como el pastel que le compraban

93 OTTE, 2008, 312.

94 Así reza una letra de cambio emitida en 1553, AHPSe: PNS, leg. 9172, f. 515.

95 AHPSe: PNS, leg. 9172, f. 552r. Los dueños eran Francisco del Alcázar y su mujer Mencía de Collantes, quienes cobraban 22.500 mrs. por cada uno de los tres años que arrendaban las casas a López.

${ }^{96}$ Así en 1554 Andrés López contrataba el navío «Nuestra Señora de Gracia» para enviarlo con su maestre de Lagos, Juan Vaez, a cargar toda la sal que cupiese en la cubierta en el puerto de las Muelas de Sevilla y en Sanlúcar de Barrameda, fondeando después en Lagos donde se cargaría cordonería, y finalmente tocando en Funchal donde el hermano de Andrés, Cristóbal López, pagaría el flete, valorado en 25.000 reales. En el tornaviaje Juan Vaez cargaría 80 cajas de azúcar que debía recibir Andrés López y que tendrían un peso de 36 arrobas, por valor de 700 mrs. cada una (AHPSe: PNS, leg. 9172, f. 560. Sevilla, 3-III-1554). El mismo Otte nos indica que en ocasiones este azúcar se reexportaba por todo el mundo mediterráneo, OTTE, 2008, 169. Obsérvese también que las exportaciones de hilo de cáñamo tenían como destino preferente debido a un acuerdo firmado con el rey de Portugal dicho país, ibidem, pág. 168.

97 Daba poder en 1554 a Miguel de Herrera para que pudiese tomar de Juan de Herrera, estante en Corte, una licencia de saca de «mil fanegas de trigo que a mi noticia es venido que el dicho Juan de Herrera tiene de merced de sus magestades o del príncipe nuestro señor para lo sacar desta Andalucia para el reino de Portugal...». AHPSe: PNS, leg. 9172, f. 523.

98 Por ejemplo, cargó en 1554 para Funchal en las naos de Bartolomé Domínguez, vecino de Tavira y de Vicente Yáñez, vecino de Lagos, toda la carga de aceite que cupiese en la primera nave, a 700 reales la tonelada en dicho caso, y a 625 reales el segundo que comportaba 70 arrobas de aceite, siendo el precio más bajo seguramente porque estaba compartido con el mercader de Madeira Juan Fernández Franco, OTTE, 2008, 147. Ese mismo año acordaba enviar aceite y otras mercancías para Funchal en la nao del vecino de Lagos Pedro Álvarez, cobrando este ducado y medio de oro por tonelada, pagando López las averías, y cargando como máximo hasta fin de abril (AHPSe: PNS, leg. 9172, f. 827r. Sevilla, 21-III-1554).

99 Entre 1554 y 1555 el confitero sevillano Hernán Sánchez, declaraba deber a Andrés López 63.150 mrs. por $7 \frac{1}{2}$ arrobas y 23 libras de canela, a 20 ducados la arroba, OTTE, 2008,188.

100 En 1555 el confitero sevillano Hernán Sánchez se constituía como su deudor de 36.900 mrs. por 4 arrobas y 23 libras de canela, debiendo pagar a fin de agosto (AHPSe: PNS, leg. 9174, f. 234r. Sevilla 4-II-1555).

101 En 1557 todavía debía 46.867 mrs. a Ludovico Valderon por 20 quintales de almendra que le habían sido remitidos desde Cádiz, junto con la letra que Valderón protestaba en 25-I-1557. AHPSe, PNS, leg. 9179, f. 171.

102 Allí enviaba en 1554 cuatro canastas de canela y un fardo de paño de la India de Portugal venidos desde Lisboa, OTTE, 2008, 189. 
diversos tintores ${ }^{103}$, o el palo brasil ${ }^{104}$. También trabajó representando a Blas Reynel y negociando con Bento Vaez, suministrándoles algunas mercancías. Sus almacenes de pastel en el corral de San Juan del Alcázar Viejo hispalense acabaron de hecho pasando a manos del yerno de Bento Vaez, Antonio Faleiro, quien continuaría con los negocios de importación de López en los años 70 y 80 del siglo.

\section{LA CULMINACIÓN DE UN PROCESO SECULAR}

Las figuras hasta aquí mencionadas, y muy especialmente Bento Vaez, representan un hito fundamental en la historia de la penetración portuguesa en la ciudad hasta 1580, año de la muerte de Vaez. Si este entró en el tejido económico sevillano de la mano de Manuel Caldeira en los años cincuenta, su progresión en el mismo y su enriquecimiento tuvo que ver con el comercio y las finanzas, pero especialmente con el comercio de esclavos. Para ello, utilizó la técnica que los portugueses ensayaron durante todo el siglo, introducirse en el seno de la propia oligarquía negrera sevillana, trabajar con ellos y para ellos, la única manera real de participar a gran escala en aquel negocio. No es casualidad que en 1561 lo encontremos trabajando para el doctor Nicolás Monardes, actuando como su fiador y pagador precisamente en la paga del precio de los derechos de las licencias para llevar a América 500 esclavos ${ }^{105}$. Como se sabe, Monardes no fue solo uno de los grandes naturalistas y médicos del siglo, sino también un activo comerciante con las Indias y uno de los principales negreros de aquellos años ${ }^{106}$.

En las décadas de los años sesenta y setenta las redes esclavistas tejidas por los portugueses adquieren ya una densidad impresionante, y fundamentalmente de la mano de ellas surge una poderosa colonia lusa en Sevilla que rivaliza, ahora sí, en poder y riqueza con los italianos que desde la Baja Edad Media habían dominado la economía de la metrópoli andaluza. En otro trabajo hemos presentado una radiografía de esos comerciantes portugueses de esclavos en el periodo 1560-1580, y dibujado una escala que va desde los minoristas que introducen esclavos desde la frontera de Huelva y Extremadura, a los que añaden la importación vía marítima desde Cabo Verde o Guinea hacia Sevilla, hasta el grupo, redu-

103 En 1555 el tintorero sevillano Bartolomé Díaz le debía 9.022 mrs. por 20 quintales y 9 libras de brasil, a 2 1/2 ducados cada quintal mientras que Diego Hernández, vecino en las Atarazanas, le adeudaba 4.088 mrs. por 4 quintales, 1 arroba y 1 libra de brasil que recibió de López, al mismo precio cada quintal, AHPSe: PNS, leg. 9174, f. 247, 7-II-1555. También ese mismo año el tintorero al mismo precio el quintal, AHPSe: PNS, leg. 9174, f. 148r, 8-I-1555.

104 En 1555 declaraba haber recibido una carga de 300 palos brasil de los cuales 59 habían sido «aserrados unos de mucho tiempo y otros de poco tiempo» no ajustándose a su peso teórico que era de 285 quintales y 300 libras, pesando cada quintal 112 libras. La mercancía había sido remitida a Sevilla por el mercader portugués y vecino de Cádiz Alvar Gramaxo (seguramente tambien portugués), quien la había recibido del mercader lisboeta Manuel Méndez, en la urca de un tal «Zamora» (AHPSe: PNS, leg. 9174, f. 213r. Sevilla, 1-II-1555).

105 AGI: Contratación, leg. 5764, fols. 11r y 36v.

106 PARDO TOMÁS, 2002, 96/102. 
cido, de los grandes negreros que manejan capitales de decenas de miles de ducados y copan buena parte del negocio de la trata atlántica. Según los datos del Almojarifazgo de esclavos para 1569-1579, encontramos en esos años 18 comerciantes que llevan a América 150 o más esclavos, entre los cuales hay cinco portugueses que controlan un tercio de los envíos de esclavos. Quien lidera la lista de forma indiscutible es Simón de Tovar, que se introduce en el negocio en 1575 y en solo cinco años envía más de 2.000 esclavos negros, continuando su actividad negrera de forma frenética durante las dos décadas siguientes. También se encuentran en esta lista Manuel Caldeira o Enrique Freire ${ }^{107}$. Tovar fue quien tomó el testigo tras el hundimiento económico de Bento Vaez en 1575-1576, liderando un grupo de portugueses estrechamente ligado con los Nunes Caldeira que se convierte en el principal lobby negrero portugués en Sevilla tras la Unión Ibérica y hasta $1595^{108}$. Cuando se produce la negociación, pujas y concesión del asiento de negros a Pedro Gómez Reynel, es Antonio Núñez Caldera quien pugna con él por el control del gran negocio ${ }^{109}$. Lo que se está produciendo a estas alturas es el choque de dos grandes lobbys portugueses por el negocio de la trata negrera, uno radicado en Sevilla y construido a lo largo de todo el siglo, y otro más reciente pero mejor instalado en la Corte, en Madrid. Esta es una historia que está aún por escribir y en la que trabajamos. Lo que sí sabemos ya es que el capital portugués, desde una presencia secundaria en la ciudad de Sevilla a comienzos del siglo XVI, supo introducirse en ella, fundamentalmente gracias a su posición líder en el negocio negrero, y desde actividades meramente mercantiles, penetró desde mediados de la centuria en los aspectos financieros de la trata, los verdaderamente lucrativos, pero para los que hacía falta disponer de gigantescos capitales que, en buena medida, fueron lucrados gracias al tráfico con seres humanos. A fines del reinado de Felipe II, el capital portugués radicado en Sevilla podía comenzar a apostar por empresas de mayor envergadura en el conjunto de la Monarquía.

\section{BIBLIOGRAFÍA}

ALMEIDA MENDES, A. de, «Portugal e o tráfico de escravos na primera metade do século XVI», Africana Studia, 7 (Oporto, 2004):13/30.

107 FERNÁNDEZ CHAVES y PÉREZ GARCÍA, 2010. PÉREZ GARCÍA y FERNÁNDEZ CHAVES, 2009, 597/622, esp. 615/616.

${ }_{108}$ Trabajo pionero y crucial sobre los Nunes Caldeira es el de FERRAZ TORRÃO, 2011. Su información conecta con la aportada hace años sobre los Freire en OTTE y RUIZ-BURRUECOS (Santander, 1963): 3/40.

${ }^{109}$ Lo ha explicado VILA VILAR, 1977, si bien el tema no está ni mucho menos agotado, como se puede colegir de una simple ojeada a la documentación conservada en AGI: Indiferente, legs. 743 ó 2975, por ejemplo. Sobre Simón de Tovar y su entorno humano y económico, la información publicada más importante es la que ofrece GIL, 1998. Una buena introducción sobre su persona es la proporcionada en LÓPEZ PÉREZ y REY BUENO (Granada, 2006): 69/91. 
ALMEIDA MENDES, A. de, «Traites ibériques entre Méditerranée et Atlantique: le noir au coeur des empires modernes et de la première mondialisation (ca. 1435-1550)", Anais de História de Além-Mar, 6 (Lisboa, 2005): 351/387.

BRAUDEL, F., El Mediterráneo y el mundo mediterráneo en la época de Felipe II, 2 vols., México,

CARANDE, M, Carlos V y sus banqueros, 2 vols., Barcelona, Critica, 1977.

CHAUNU, P., Séville et l'Atlantique (1504-1650). París, SEVPEN, 1959.

CORTÉS LÓPEZ, J. L.: «Importancia de la esclavitud en la expansión portuguesa en África y su repercusión en el mundo hispánico», en A. M. CARABIAS TORRES (ed.), Las relaciones entre Portugal y Castilla en la época de los descubrimientos y la expansión colonial, Salamanca, Universidad de Salamanca, 1994: 249/269.

FERNÁNDEZ ÁLVAREZ, M., Corpus documental de Carlos V, vol. 3, Salamanca, Universidad de

FERNÁNDEZ CHAVES, M. F. y PÉREZ GARCÍA, R. M., «La esclavitud en la Sevilla del Quinientos: reflexión histórica (1540-1570)", en F. Lorenzana De La Puente y F. J. Mateos Ascacíbar (coords.), Marginados y minorías sociales en la España moderna y otros estudios sobre Extremadura, Llerena, Sociedad Extremeña de Historia, 2005: 123/133.

- En los márgenes de la Ciudad de Dios. Moriscos en Sevilla, Valencia, Editorial Universidad de Granada, 2009.

- «Las redes de la trata negrera. Mercaderes portugueses y tráfico de esclavos en Sevilla (c. 1560-1580)", en A. Martín Casares y M. García Barranco (comps.), La esclavitud negroafricana en la historia de España. Siglos XVI y XVII, Granada, Comares, 2010: 5/34.

- «América como mecanismo de transformación y movilidad social en la Sevilla moderna: los Caballero de Cabrera», en Miguel Jasmins Rodriguez y Maria Manuel Torrão (coords.): Pequena Nobreza de Aquém e de Além-Mar. Poderes, Patrimónios e Redes, Lisboa, IICT, 2011.

- «La trata negrera: Bento Vaez y la consolidación del capitalismo portugués en Sevilla. Ca. 1550-1580». En prensa.

FERRAZ TORRAO, M. M., Tráfico de escravos entre a Costa da Guiné e a América Espanhola. Articulação dos impérios ultramarinos ibéricos num espaço Atlântico (1466-1595), Lisboa, 1999, Dissertação para efeitos de prestação de Provas de Acceso à Categoria de Investigador Auxiliar.

- «Formas de participação dos portugueses no comércio de escravos com as Índias de Castela: abastecimiento e transporte», en A Dimensão Atlântica da África, Lisboa, Vega, 2002.

- «Quando é importante controlar e conservar a informação». Relações de confiança e casamentos de conveniência: meios de gestão do tráfico negreiro entre as ilhas de Cabo Verde e a América Espanhola na segunda metade do século XVI», en Miguel Jasmins Rodrígues y Maria Manuel Torrão (coords.), Pequena nobreza de Aquém e de Além-Mar. Poderes, Patrimonios e Redes, Lisboa, IICT, 2011: 43/63.

- «Os portugueses e o trato de escravos de Cabo Verde com a América Espanhola» en Cardim, Freire Costa y Soares da Cunha (orgs.): Portugal na Monarquia Hispânica. Dinâmicas de integração e conflito, Lisboa, CHAM-Red Columnaria, 2013: 93/106.

FONSECA, J., Os escravos em Évora no século XVI, Évora, câmara Municipal de Évora, 1997.

- Escravos no sul de Portugal, Lisboa, Vulgata, 2002.

- Escravos e Senhores na Lisboa Quinhentista, Lisboa, Colibri, 2010.

FRANCO SILVA, A.: «La intervención de Portugal en el comercio de esclavos de Andalucía a fines del Medievo", Actas del III Coloquio de Historia Medieval Andaluza, Jaén, Diputación, 1984: 339/349.

GARCÍA FIGUERAS, T., «Los factores portugueses en Andalucía en el siglo XVI», Archivo hispalense, 23/24 (Sevilla, 1948):1/41.

GIL, J., «De Sevilla a Lisboa: Aspectos de una relación secular», Portuguese Studies, 8 (Londres, 1992): 40/56.

- Arias Montano y su entorno. Bienes y herederos, Badajoz, Editora Regional, 1998. 
- El exilio portugués en Sevilla. De los Braganza a Magallanes, Sevilla, Fundación Cajasol, 2009.

GÓMEZ ZÚÑIGA, P., Minería aurífera, esclavos negros y relaciones interétnicas en la Honduras del siglo XVI (1524-1570), Tegucigalpa, Instituto Hondureño de Antropología e Historia, 2012.

GORIS, J. A., Étude sur les colonies marchandes méridionales (portugais, espagnols, italiens) à Anvers de 1488 à 1567, Louvain, Uystpruyst,1925.

IGUAL LUIS, D., "Valencia y Sevilla en el sistema económico genovés de finales del siglo XV», Revista d'Historia Medieval, 3 (Valencia, 1992): 79/116.

KELLENBENZ, H., Sephardim an der unteren Elbe. Ihre wirtschaftliche und politische Bedeutung vom Ende des 16 bis zum Beginn des 17, Wiesbaden, Jahrhunderts,1958.

KELLENBENZ, H. y ROLF, W., Oberdeutsche Kaufleute in Sevilla und Cadiz. Eine edition von notariatsakten aus den dortigen archiven, Stuttgart, 2001,

LADERO QUESADA, M. A., Historia de Sevilla. La ciudad medieval, Sevilla, Universidad de Sevilla, 1989.

LÓPEZ BELTRÁN, Ma․ T. y GONZÁLEZ ARÉVALO, R., «Los portugueses en el Reino de Granada en época de los Reyes Católicos (Málaga, 1487-1518)», Baetica, 24 (Málaga, 2002): 309/338.

LÓPEZ BELTRÁN, María Teresa, "La oligarquía mercantil judeoconversa del Reino de Granada en época de los Reyes Católicos: la proyección internacional de los Córdoba-Torres», en M. C. Barbazza y C. HEUSCH (eds.): Familles, Pouvoirs, Solidarités. Domaine méditerranéen et hispano-américain (Xve-XXe), Montpellier, Université Montpellier III, 2002: 397/419.

LÓPEZ DE COCA CASTAÑER, J. E., «Portugal y Granada: presencia lusitana en la conquista y repoblación del reino granadino (siglos XV-XVI)", El Reino de Granada en la época de los Reyes Católicos: repoblación, comercio y frontera, 2 vols., Granada, Universidad de Granada, 1989.

LÓPEZ PÉREZ, M. y REY BUENO, M., «Simón de Tovar (1528-1596): redes familiares, naturaleza americana y comercio de maravillas en la Sevilla del XVI», Dynamis, 26 (Granada, 2006): $69 / 91$.

LORENZO SANZ, E., Comercio de España con América en la época de Felipe II, 2 vols., Valladolid, diputación Provincial de Valladolid, 1979.

MATEUS VENTURA, M. da G., Negreiros portugueses na rota das Índias de Castela (1541-1556), Lisboa, Colibri, 1999.

MIRA CABALLOS, E., «Las licencias de esclavos negros a Hispanoamérica (1544-1550)», Revista de Indias, 54 (Madrid, 1994): 273/297.

MORALES PADRÓN, F., Historia de Sevilla. La ciudad del Quinientos, Sevilla, Universidad de Sevilla, 1989.

OTTE, E. y RUIZ-BURRUECOS, C., «Los portugueses en la trata de esclavos negros de las postrimerías del siglo XVI», Moneda y crédito, 85 (Santander, 1963): 3/40.

OTTE, E, "Sevilla, plaza bancaria europea en el siglo XVI», en A. Otazu y Llana, de (ed.): Actas del I Coloquio Internacional de Historia Económica. Dinero y Crédito (siglos XVI al XIX), Madrid, 1978.

- Sevilla y sus mercaderes a fines de la Edad Media. Sevilla, Fundación El Monte, 1996.

- "Cuentas de dos compañías del pastel de las islas de las Azores de 1558 y 1559», Historia. Instituciones. Documentos, 30 (Sevilla, 2003): 429/467.

- Sevilla, siglo XVI: Materiales para su historia económica, Sevilla, Centro de Estudios Andaluces, 2008.

PARDO TOMÁS, J., El tesoro natural de América. Colonialismo y ciencia en el siglo XVI: Oviedo. Monardes. Hernández, Madrid, Nivola, 2002.

PASTORINO, S, «La participación de los mercaderes ligures en el mercado asegurador valenciano (1519-1520)» en Herrero Sánchez, Ben Yessef, Garfia, Bitossi y Puncuh (coords.): 
Génova y la Monarquía Hispánica (1528-1713), Génova, Societá Ligure di Storia Patria, 2011:219/249.

PERAZA, L. de, Historia de Sevilla, transcripción, estudio y notas por Francisco Morales Padrón, Sevilla, Asociación Amigos del Libro Antiguo, 1996.

PÉREZ GARCÍA, R. M. y FERNÁNDEZ CHAVES, M. F.: «Sevilla y la trata negrera atlántica: envíos de esclavos desde Cabo Verde a la América española, 1569-1579", en Álvarez Santaló (coord.): Estudios de Historia Moderna en Homenaje al Profesor Antonio García-Baquero, Sevilla, Universidad de Sevilla, 2009: 597/622.

PIKE, R., Enterprise and adventure. The Genoese in Seville and the opening of the New World, Ithaca, Cornell University Press, 1966.

RAMOS, D., «El negocio negrero de los Welser y sus habilidades monopolísticas», Revista de Historia de América, 81 (Méjico, 1976): 7/10.

RAU, V., «Um grande mercador-banqueiro italiano em Portugal: Lucas Giraldi», Estudos italianos em Portugal, 24 (Lisboa, 1964/1965): 3/35.

RODRÍGUEZ MOREL, G.: «Esclavitud y vida rural en las plantaciones azucareras de Santo Domingo. Siglo XVI», Anuario de Estudios Americanos, 49 (Sevilla, 1992):101/102.

RUIZ MARTÍN, F.: Pequeño capitalismo, gran capitalismo. Barcelona, Crítica, 1990.

SCELLE, G., La traite négrière aux Indes de Castille, 2 vols., Paris, Sirey, 1906.

ULLOA, M., La hacienda real de Castilla en el reinado de Felipe II, Madrid, Fundación Universitaria Española, 1977.

VAN KLAVEREN, Jacob, Europäische Wirtschaftgeschichte Spaniens im 16. und 17. Jahrhundert, Stuttgart, Gustav Fischer Verlag, 1960.

VARGAS-ZÚÑIIGA Y MONTERO DE ESPINOSA, A. y CUARTERO Y HUERTA B: Índice de la colección de don Luis de Salazar y Castro, tomo IV, Madrid, Real Academia de la Historia, 1950.

VILA VILAR, E., Hispanoamérica y el comercio de esclavos, Sevilla, Escuela de. Estudios Hispanoamericanos, 1977. 